\title{
Analysis of Immune Markers and Hematological Features in Plasmodium/Dengue Virus Co-infected Patients in Ouagadougou, Burkina Faso
}

\author{
Yeri Esther Hien ${ }^{1, *}$, Fatimata Thiombiano ${ }^{1}$, Denise P. Ilboudo ${ }^{1,2}$, Donatien Kima ${ }^{1}$, Siaka Kobeane ${ }^{3}$, \\ Gertrude Marilyse Relwende Sawadogo ${ }^{1}$, Y. Caleb Tindano ${ }^{4}$, Guillaume S. Sanou ${ }^{1}$, Jacques Simpore ${ }^{2}$, \\ Lassana Sangare ${ }^{5}$, Yves Traore ${ }^{1}$

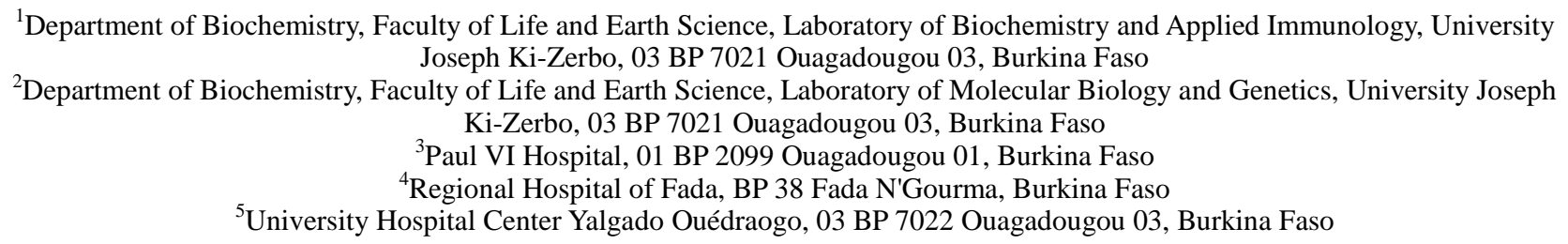

Received September 9, 2021; Revised November 18, 2021; Accepted November 28, 2021

\section{Cite This Paper in the following Citation Styles}

(a): [1] Yeri Esther Hien, Fatimata Thiombiano, Denise P. Ilboudo, Donatien Kima, Siaka Kobeane, Gertrude Marilyse Relwende Sawadogo, Y. Caleb Tindano, Guillaume S. Sanou, Jacques Simpore, Lassana Sangare, Yves Traore, "Analysis of Immune Markers and Hematological Features in Plasmodium/Dengue Virus Co-infected Patients in Ouagadougou, Burkina Faso," Immunology and Infectious Diseases, Vol. 9, No. 2, pp. 11 - 19, 2021. DOI: 10.13189/iid.2021.090201.

(b): Yeri Esther Hien, Fatimata Thiombiano, Denise P. Ilboudo, Donatien Kima, Siaka Kobeane, Gertrude Marilyse Relwende Sawadogo, Y. Caleb Tindano, Guillaume S. Sanou, Jacques Simpore, Lassana Sangare, Yves Traore (2021). Analysis of Immune Markers and Hematological Features in Plasmodium/Dengue Virus Co-infected Patients in Ouagadougou, Burkina Faso. Immunology and Infectious Diseases, 9(2), 11 - 19. DOI: 10.13189/iid.2021.090201.

Copyright@2021 by authors, all rights reserved. Authors agree that this article remains permanently open access under the terms of the Creative Commons Attribution License 4.0 International License

\begin{abstract}
Malaria and dengue are two important vector -borne infections that are common in tropical countries. In these areas, simultaneous occurrence of malaria and dengue in an individual cannot be excluded, although published reports of co-infections are scarce till date. The Aims of this study were to identify dengue and malaria co-infection cases as well as to ascertain the severity of dengue and malaria in co - infection based on some hematological parameters. A cross-sectional study was conducted from June to November 2019 and 385 subjects with an undifferentiated febrile illness patients were recruited at outpatient clinics and blood sample were collected. All samples were tested for dengue NS1 antigen and for dengue IgM/IgG. Malaria diagnosis was based on the identification of Plasmodium parasites on a thin and thick blood films microscopy. Among the 385 patients included in the study, $23.9 \%$ were tested positive for
\end{abstract}

malaria, 32.5\% were positive for dengue, and $7.01 \%$ showed concurrent infection of both malaria and dengue. Malaria and dengue co-infected patients presented lower leukocytes level (5.024 \pm 0.559$)$ than malaria monoinfected patients (7.304 $\pm 0.388 ; p=0.002)$. A significant reduction in platelet counts was observed in co-infected patients $(164.0 \pm 10.91$ vs $229.1 \pm 14.32 ; p=0.005)$. Conversely, hemoglobin level was statistically lower in malaria monoinfected patients than dengue monoinfected patients ( $p=0.014)$. Thus this study demonstrates that the diagnosis of dengue and malaria should be carried out routinely for better management of fever.

Keywords Malaria, Dengue, Coinfection, Ouagadougou, Burkina Faso 


\section{Introduction}

Malaria is the most important mosquito-borne parasitic disease, which causes a larger number of deaths in the world especially in Africa. Women and children under 5 years are most affected in terms of mortality. In 2018, 219 millions cases were reported and 445,000 deaths registered worldwide [1]. Malaria persists despite multiple strategies to eradicate it. The recent strategies are based on diagnosis, early care of malaria cases and vector control. In Burkina Faso, Malaria is still endemic and remains a veritable public health concern. Each year, the number of cases and deaths caused by malaria is high and this disease remains the main cause of death in Burkina Faso [2].

Dengue is currently regarded as the most prevalent mosquito-borne viral disease worldwide and is described as a "neglected" tropical disease by the World Health Organization (WHO). In the last five years, cases of dengue fever were consistently recorded in Burkina Faso. During the 2016 outbreak in the capital of Burkina Faso, WHO had reported a total of 1,061 probable dengue cases out of 1266 suspected cases with a cumulative total of 15 deaths (case fatality rate of 1.2\%) between August and November 2016 [3, 4]. But these cases were probably underestimated in a context where malaria is endemic. Another recent study had revealed that the prevalence of dengue nonstructural protein antigen (NS1Ag) was 22.5\% and $13.3 \%$ in the study population in Burkina Faso, in 2016 and 2017 respectively [5].

Although Anopheles and Aedes, the mosquito vector of malaria and dengue virus (DENV) respectively, occupy different ecological niches, considerable geographical overlap in disease risk exists for the 3.3 and 4.0 billion people who live in an endemic area for malaria and dengue, respectively [6, 7]. In addition, malaria and dengue fever share many common clinical features including fever, headache, body aches, and fatigue, making one disease easily mistaken for the other. However, in malaria-endemic areas, more than $70 \%$ of febrile illnesses are treated as presumptive malaria, often without proper medical examination and without laboratory diagnosis. In this context, there is a problem of differential diagnosis with a real risk of misdiagnosis of dengue fever as malaria [8]. Therefore, it is important to have the right diagnosis in order to properly respond to the disease and know which drug to take or not.

Given the endemicity of dengue and malaria in Burkina Faso [9], it is reasonable to envisage that the occurrence of concurrent infections would not be rare. Nevertheless, reports of malaria and dengue co-infection are scarce. The general objective of the present study was to determine the prevalence of malaria and dengue co-infection in patients presenting clinical symptoms and to understand the impact on platelet, leukocytes and hemoglobin.

\section{Materials and Methods}

\subsection{Study Area}

This study was carried out at CMA Paul VI, a peripheral health center of Ouagadougou the capital of Burkina Faso. Burkina Faso is malaria endemic country characterized by a dry and rainy season. The transmission of malaria is stable and seasonal. The high peak of transmission is observed during the rainy season between May and November (in Banfora and Niangologo), and between June and October in Ouagadougou [10]. The main species of Plasmodium, which causes mortality, is Plasmodium falciparum ( $P$. falciparum), and the main vectors are Anopheles gambiae and Anopheles funestus.

In Burkina Faso, the magnitude of dengue virus (DENV) transmission is largely unknown, several outbreaks have been reported and data are often based on findings from outbreak investigations. Dengue Fever is caused by four related but antigenically distinct viruses (DENVs, serotypes 1-4). DENV 2 was the main serotype in circulation during the outbreak in 2016, whereas DENV 3 was the main serotype before the outbreak [11].

\subsection{Study Population}

Table 1. Baseline characteristics of patients

\begin{tabular}{cc}
\hline Variables & $\mathbf{N}(\%)$ \\
\hline Gender & $157(40.8)$ \\
Male & $228(59.2)$ \\
Female & $\mathbf{2 5 . 7 \pm 1 6 . 0}$ \\
\hline Mean Age \pm SD & \\
Age group (year) & $52(13.5)$ \\
\hline ] 5-15] & $57(14.8)$ \\
] 15-25] & $84(21.8)$ \\
] 25-35] & $75(19.5)$ \\
$>35$ & $117(30.4)$ \\
\hline Total & $385(100)$ \\
\hline
\end{tabular}

From June 2019 to November 2019, 385 subjects with an undifferentiated febrile illness were recruited at outpatient clinics at the CMA Paul VI of Ouagadougou and screened for malaria and dengue fever. The study population was sampled as following. We estimated that people at risk represents $50 \%$ with a general population in Ouagadougou estimated at 3,000,000. We also considered confidence intervals at $5 \%$ with a confidence level fixed at 95\%. The volunteers enrolled in this study were 385 . Among them 228 were females (59.22\%) and 157 were males $(40.78 \%)$, the sex ratio was 0.69 . Patients' age ranged from 0 and 78 years with an average of $25.7 \pm 16.0$. Children who have 5 years or less accounted for $13.5 \%$ 
(52/385) while $14.8 \%$ (57/385) of participants were 5 to 15 years old and $276(71.7 \%)$ participants above 15 years old (Table 1). After inclusion, blood sample was collected from each subject for laboratory analyzes. A structured questionnaire was used to collect some relevant socio-demographic data.

\subsection{Blood Sampling}

Finger prick blood was collected to prepare a slide with thick and thin blood films for each study volunteer. For the purpose of hematological and dengue assessment, four milliliters of blood sample were collected into an ethylene diamine tetra-acetic acid (EDTA) tube from each patient meeting the study inclusion criteria. A laboratory processed the samples within 3 hours of collection.

\subsection{Malaria Diagnosis}

Thick and thin blood smears were collected and stained with $6 \%$ Giemsa and examined by experienced microscopists for microscopic diagnosis of malaria. The number of malaria parasites of each species and stage were recorded. The number of parasites per $\mu$ l of blood was calculated according to the leucocyte count obtained after the full blood count for each slide collected during the malaria transmission season. A slide was declared negative if no parasite was seen after 200 HPF (High Power Field) examination.

\subsection{Dengue Diagnosis}

Detection of dengue virus infection was performed from serum or plasma using the SD BIOLINE Dengue DUO® rapid immunochromatographic test kit (Standard Diagnostic Inc., Korea). The SD BIOLINE Dengue Duo is produced by Standard Diagnostics and is a one-step immunochromatographic assay designed for the detection of both dengue virus NS1 antigen and differential IgM/IgG antibodies to dengue virus in human whole blood, serum, or plasma. The manufacturer's instructions for AgNS1 and IgG/IgM immunochromatographic tests were followed as described previously [12]. Briefly, 100 $\mu \mathrm{l}$ and $10 \mu \mathrm{l}$ of serum specimen were added to the sample well "S" of the AgNS1 and IgM/IgG strips of the combo device, respectively. Four drops of assay diluents were added to the assay diluent well of the latter. Both strips of the device were read at $15-20 \mathrm{~min}$. This assay has a sensitivity of 88.65\% (95\% CI: 84.04-93.26), a specificity of $98.75 \%$ (95\% CI: 96.26-100) with an assay efficiency of $91.70 \%$ [12]. Current or recent dengue infection was defined on the basis of a positive result for NS1 Ag and / or IgM. Past infection was defined on a basis of a positive result of IgG alone.

\subsection{Hematological Analyses}

Hematological features were analyzed as described by
Kima et al (2020) [13]. Blood samples collected in EDTA tubes were used for whole blood count in all patients using the hematology analyzer XNL-350TM from SYSMEX Corporation (Kobe, Tokyo, Japan) following the manufacturer's instructions. The blood constituent as leukocytes, platelets and hemoglobin level was given.

\subsection{Statistical Analysis}

The data were analyzed using the SPSS IBM for Windows software version 17.0 Hematological characteristics from the group of patients co-infected with dengue and malaria were compared to the group of patients-mono-infected with dengue and the group of patients-mono-infected with malaria. The chi-squared test was used for comparisons, and each value was considered statistically significant for $\mathrm{p} \leq 0.05$.

\subsection{Ethics Statement}

The institutional ethic committee approved this study. After being informed of the study, written consent was obtained from all participating adults or from a parent or legal guardian of subjects under 17 years old. Assent was also obtained from subjects between ages 5-17 years old. Parents and Participants were ensured of confidentiality, by attribution of codified identification numbers.

\section{Results}

\subsection{Prevalence of Malaria Infection and Parasite Densities According to Age in the Study Population}

The prevalence of malaria in our study population was $23.9 \%$ and the geometric mean of $P$. falciparum asexual stages was $5323 \pm 1773$ parasites $/ \mu$ L. Prevalence of $20.4 \%$ (32/157) and 26.3\% (60/228) was observed for men and women, respectively. Analysis of the prevalence according to age groups showed that the prevalence slightly increases with age. Prevalence was $23.1 \%$ for patients who have 5 years or less, $28.1 \%$ for patient aged between $5-15$ year and $28.6 \%$ for subjects aged 15 to 25 years. The other age groups had shown prevalence around $20 \%$. We did not observe any difference between the prevalence in men and in women, as well as the prevalence in the different age groups of patients. Malaria parasite densities were more important in subjects who are aged 5 years or less $(13302 \pm 2820$ parasites/uL) than subjects aged more than 5 years. The lowest parasitaemia was observed in patients aged 25 to 35 years (579 parasites/uL). Table 2 summarizes the prevalence of malaria and parasite densities in the study population according to age and gender. 


\subsection{Prevalence of Dengue Fever Virus Antigen and Antibodies}

AgNS1 was detected in 30,9\% (119/385) of people included in the study. According to gender we found a prevalence of 36.9\% (58/385) in men and 26.8\% (61/385) in women. Men were significantly more infected with the dengue virus $(\mathrm{AgNS1}+)$ compared to women $(p=0.017)$. According to patients' age, prevalence of AgNS1 was $23.1 \%$ in patients who are aged 5 years or less, $24.6 \%$ for patients aged between 5-15 years and $38.1 \%$ in subjects aged 15 to 25 years (Table 3). Prevalence of AgNS1 was significantly higher in the age group 15-25 than in younger age group patients. Unlike the prevalence of
AgNS1, the prevalence of IgG and IgM against dengue virus was low. Prevalence of $1.6 \%(6 / 385)$ and $7.5 \%$ (29/385) were observed for IgM and IgG, respectively. We also analyzed the co-expression of DENV specific antigen and antibodies in our study population. DENV-specific antigen was detected with IgM in $0.3 \%$ of patients whereas IgG were detected with DENV-specific antigen in $0.8 \%$ of patients. The highest proportions of IgM and IgG were observed in AgNS1 positive patients. Indeed, among AgNS1 positive patients 30.6\% were IgM negative and $30.1 \%$ were IgG negative (table 4). In AgNS1 negative patients, IgM and IgG were detected respectively in $1.3 \%$ and $6.7 \%$ of patients.

Table 2. Malaria prevalence and parasites densities according to age

\begin{tabular}{|c|c|c|c|c|c|}
\hline Characteristics & n (\%) & OR & Malaria status CI 95 \% & p-Value & Parasitaemia /uL \\
\hline P. falciparum infection & $92(23.9)$ & - & - & - & \\
\hline Mean Parasitemia ${ }^{a}$ & & - & - & - & $5323 \pm 1773$ \\
\hline \multicolumn{6}{|l|}{ Gender } \\
\hline Male & $32(20.4)$ & Ref & - & - & $4366 \pm 1784$ \\
\hline Female & $60(26.3)$ & 0.72 & [0.44-1.17] & 0.09 & $5853 \pm 1591$ \\
\hline \multicolumn{6}{|l|}{ Age group (year) } \\
\hline$\leq 5$ & $12(23.1)$ & 0.75 & [0.34-1.67] & 0.24 & $13302 \pm 2820$ \\
\hline ] 5-15] & $16(28.1)$ & 0.98 & {$[0.46-2.07]$} & 0.47 & $5222 \pm 1085$ \\
\hline ] 15-25] & $24(28.6)$ & Ref & - & - & $8096 \pm 2344$ \\
\hline ] 25-35] & $16(21.3)$ & 0.63 & {$[0.30-1.31]$} & 0.11 & $579 \pm 41$ \\
\hline$>35$ & $24(20.5)$ & 0.65 & [0.34-1.24] & 0.09 & $2215 \pm 488$ \\
\hline
\end{tabular}

${ }^{a}$ Geometric mean; parasites $/ \mathrm{mm}^{3}$

Table 3. Prevalence of dengue single markers in study population

\begin{tabular}{|c|c|c|c|c|c|c|}
\hline Variables & AgNS1+ n(\%) & OR & NS1Ag status CI $95 \%$ & $p$-value & $\operatorname{IgM}+\mathbf{n}(\%)$ & $\begin{array}{l}\text { IgG+ } \\
\text { n(\%) }\end{array}$ \\
\hline $\begin{array}{c}\text { Dengue single } \\
\text { markers }\end{array}$ & 119 (30.9) & - & - & - & $6(1.6)$ & $29(7.5)$ \\
\hline \multicolumn{7}{|l|}{ Per gender } \\
\hline Men & 58 (36.9) & Ref & - & - & $4(2.6)$ & $10(6.4)$ \\
\hline Women & $61(26.8)$ & 1.6 & [1.04-2.48] & $0.017 *$ & $2(0.9)$ & $19(8.3)$ \\
\hline \multicolumn{7}{|l|}{$\begin{array}{c}\text { Per age group } \\
\text { (year) }\end{array}$} \\
\hline$\leq 5$ & $12(23.1)$ & 0.49 & [0.22-1.07] & $0.034^{*}$ & $2(3.8)$ & $2(3.8)$ \\
\hline ] 5-15] & $14(24.6)$ & 0.53 & {$[0.25-1.12]$} & $0.046^{*}$ & $0(0.0)$ & $4(7.0)$ \\
\hline ] 15-25] & $32(38.1)$ & Ref & - & - & $0(0.0)$ & $5(5.9)$ \\
\hline ] 25-35] & $28(37.3)$ & 0.97 & [0.51-1.84] & 0.461 & $1(1.3)$ & $6(8.0$ \\
\hline$>35$ & $33(28.2)$ & 0.64 & {$[0.35-1.16]$} & 0.07 & $3(2.6)$ & $12(10.3)$ \\
\hline
\end{tabular}

$* \mathrm{p} \leq 0.05$ 
Table 4. Serological profile of dengue virus infection in the study population

\begin{tabular}{cccc}
\hline & AgNS1 Positive & AgNS1 Negative & Total \\
\hline IgM & $\mathrm{n}(\%)$ & $\mathrm{n}(\%)$ & $\mathrm{n}(\%)$ \\
Positive & $1(0.3)$ & $5(1.3)$ & $6(1.6)$ \\
Negative & $118(30.6)$ & $261(67.8)$ & $379(98.4)$ \\
\hline IgG & & & $29(7.5)$ \\
Positive & $3(0.8)$ & $26(6.7)$ & $356(92.5)$ \\
Negative & $116(30.1)$ & $240(62.4)$ & $385(100)$ \\
\hline Total & $119(30.9)$ & $266(69.1)$ & \\
\hline
\end{tabular}

Table 5. Prevalence of dengue markers combined with plasmodium detection

\begin{tabular}{|c|c|c|c|c|c|c|c|c|c|}
\hline & & \multicolumn{4}{|c|}{ AgNS1 + n(\%) } & \multicolumn{4}{|c|}{ AgNS1 - n(\%) } \\
\hline & & IgM + & IgM - & IgG + & IgG - & IgM+ & IgM- & Ig G+ & IgG- \\
\hline \multirow{2}{*}{$\begin{array}{l}\text { Thick } \\
\text { /blood film }\end{array}$} & + & $0(0.0)$ & $26(6.8)$ & $1(0.3)$ & $25(6.5)$ & $1(0.3)$ & $\begin{array}{c}65 \\
(16.9)\end{array}$ & $11(2.9)$ & $\begin{array}{c}55 \\
(14.3)\end{array}$ \\
\hline & - & $1(0.3)$ & 92 (23.9) & $2(0.5)$ & 91 (23.6) & $4(1.0)$ & 196 (50.9) & $15(3.9)$ & $\begin{array}{c}185 \\
(48.1)\end{array}$ \\
\hline
\end{tabular}

Table 6. Laboratory findings of patients with $P$. falciparum, dengue fever and $P$. falciparum and dengue fever co-infection in the peripheral health center of Ouagadougou in Burkina Faso.

\begin{tabular}{cccccc}
\hline Variables & P. falciparum (A) & Dengue (B) & Co-infection (C) & A $\times \mathbf{C}$ & B $\times \mathbf{C}$ \\
\hline & & & & $p$ & $p$ \\
Parasitemia & & & $\mathrm{n}=27$ & & \\
Leukocytes $\times 10^{3}$ cell/ul & $5561 \pm 1926$ & $\mathrm{n}=92$ & $5611 \pm 1711$ & 0.536 & $\mathrm{NA}$ \\
Platelets $\times 10^{3}$ cell/ul & $7.3 \pm 0.4$ & $\mathrm{NA}$ & $5.0 \pm 0.6$ & $0.002^{*}$ & 0.288 \\
Hemoglobin $(\mathrm{g} / \mathrm{dl})$ & $229.1 \pm 14.3$ & $187.7 \pm 8.5$ & $164.0 \pm 10.9$ & $0.005^{*}$ & 0.338 \\
\hline
\end{tabular}

${ }^{a}$ Geometric mean; parasites $/ \mathrm{mm}^{3}$. ${ }^{*} \leq 0.05$

\subsection{Plasmodium/Dengue Virus Co-infection}

Dengue and malaria co-infection was defined by a thick blood film positive for Plasmodium and the presence of one of the dengue acute phase markers AgNS1 and IgM. In total, 7.01\% (27/385) of patients were co-infected with dengue and malaria in our study population. The proportion of co-infected patients was 29.35\% among malaria patients and $22.69 \%$ among those infected with dengue. According to AgNS1 detection, 6.8\% of volunteers were AgNS1 positive and thick/thin blood smears positive. However, $0.3 \%$ of malaria positive patients had IgM positive (table 5).

\subsection{Hematological Features of Infected Patients}

Table 6 compares hematological data and parasitemia between malaria-monoinfected patients, dengue-monoinfected patients and malaria-dengue co-infected patients. We did not find any difference between Plasmodium parasitemia in malaria-monoinfected and in co-infected patients. In contrast, malaria-dengue co-infected patients had shown a lower leukocytes level than malaria -monoinfected patients; the difference was statistically significative at $p=0.002$.

Compared to malaria mono-infected patients, dengue monoinfected patients and malaria-dengue co-infected patients presented a significant $(p=0.005)$ reduction in platelet counts although platelet count was not statistically $(p=0.338)$ different between dengue single-infected patients and malaria-dengue co-infected patients.

Conversely, hemoglobin level was lower in malaria-monoinfected patients than dengue-monoinfected patients $(p=0.014)$, while there was no difference between the hemoglobin level in malaria-monoinfected patients and malaria-dengue co-infected (table 6). This observation is consistent with the fact that the malaria parasite infects red blood cells in the erythrocytes phase.

\section{Discussion}

Dengue is an important emerging disease in tropical and sub-tropical regions where malaria is still endemic. It 
is clear that since the last decade, dengue has been occurring regularly with periodic surges in a number of cases [14]. In Burkina Faso, several outbreaks of dengue infection have been reported and malaria transmission is stable and seasonal. The high peak of malaria transmission is observed during the rainy season between May and November (in Banfora and Niangologo); June and October in Ouagadougou. $[10,15]$. In this study, $23.9 \%$ patients were infected by $P$. falciparum. These data are similar to those in the majority of endemic areas and confirm that malaria is still endemic in Burkina Faso [1].

Analysis of parasitaemia in patients infected with Plasmodium showed that parasitaemia decrease with age because of the presence of some immunity in older subjects. The exposition to malaria for several years allowed elder subjects to acquire a form of immunity, which induced rapid parasites elimination. But this immunity did not last long [16].

However, subjects less than 5 years who suffered from malaria had high parasitaemia. The immaturity of their immune system did not allow them to clear parasites more quickly than the elder subjects [17-20]. The prevalence of malaria seemed to increase with age, although it was not statistically significant. Indeed, prevalence was $23.08 \%$ for patients who have 5 years or less, $28.07 \%$ for patients aged between 5-15 years and $28.57 \%$ for subjects aged 15 to 25 years. In malaria endemic areas, children less than 5 years who received seasonal prophylaxis were treated with sulfadoxine pyrimethemime. This treatment prevented malaria [21]. Therefore, the prevalence of malaria in this age group was not so important compared to that in elder subjects who did not received this chimioprophylaxie.

DENV is rapidly spreading as the result of urbanization, climate changes and increased human migration. DENV has emerged as the most common vector-borne viral infection in the current century. The virus occurred primarily in rural areas, but has recently become of urban distribution due to development of extensive urbanization in rural areas. Diagnosis of acute infection of dengue virus in this study was based on the presence AgNS1 and/or dengue specific IgM [22].

The presence of AgNS1 and IgM suggest an early infection with the dengue virus. In this study, the prevalence of dengue NS1 antigen without IgM was $30.6 \%$. However IgM has been detected in $1.6 \%$ of participants giving an overall prevalence of $32.2 \%$. For acute dengue infection, the high prevalence of AgNS1 recorded in this study could be explained by the fact that most of the infected patients were in the acute phase of the infection. The NS1 antigen was detectable from the first day after the onset of the disease. In contrast to AgNS1 detection, anti-dengue IgM and IgG antibodies were not detectable before day 3 of illness. The prevalence of dengue NS1 antigen was similar to other studies from Burkina Faso [5]. The high prevalence of AgNS1 in our study population confirmed high endemicity of dengue infection, active transmission of disease and proved that dengue fever was also a public health concern in Burkina Faso in addition to malaria [23, 24].

In this study, men were significantly more affected by acute dengue infection $(\mathrm{OR}=1.604,95 \%$ IC $=$ [1.036-2.483], $\mathrm{p}=0.034)$. These findings correlate well with others studies undertaken in North and South India and in Burkina Faso [5, 25-28]. High prevalence amongst males is probably due to more outdoor activities by males in comparison to females, which results in more exposure to day biting mosquitoes. In contrast to dengue fever, the difference of prevalence of malaria was not statistically significant between men and women (OR $=0.717,95 \%$ IC $=$ [0.44-1.167], $\mathrm{p}=0.180$ ). This could be explained by the differential exposure of men and women to dengue vectors compared to malaria.

In addition to the markers of the acute phase of dengue fever, we also analyzed IgG antibody. In dengue infection, IgG is the marker of serologic scar or late stage of infection. The positivity of AgNS1 and IgM allows to make the diagnosis of an early infection while IgG appear earlier during the course of secondary infection [29].

The presence of IgG in addition to AgNS1 allowed to distinguish the acute phase of secondary infections from past infection serological scars. In this study, IgG only were detected in $6.7 \%$ while $0.8 \%$ have AgNS1 and IgG. The positivity to IgG antibodies only, indicated a past dengue infection [22]. The simultaneous detection of AgNS1 and IgG meant secondary infections that reflected an active transmission of dengue virus in our populations with a risk of severe cases [30].

In Ouagadougou, an endemic area of dengue fever and malaria, we found a high prevalence of the co-infection (7.01\%). A prospective study performed in 2009 on 132 patients in Brazilia found $8.3 \%$ of co-infection dengue-vivax malaria [31]. The prevalence of co-infection was 5.8\% among all cases of fever during a dengue outbreak in India [32]. Our result was similar to the result found in the French Guiana and Brazilia, with prevalence of co-infection of $7.1 \%$ and $7 \%$ respectively among patients with dengue [31, 33]. However, a higher prevalence was found in Pakistan (23.2\%) [34]. This suggests that the prevalence of co-infection may fluctuate depending on local endemicity and seasonal period and local community behavior. The present study was carried in outpatient clinics thereby, in-part reflecting the community scenario. We believe these results cannot be extrapolated to hospitalized patients with severe malaria or dengue.

Leucopenia is usually observed in the course of dengue fever which is due to direct marrow suppression by the dengue virus [35]. Analysis of leukocyte in our study population showed a lower leukocytes level in dengue monoinfected patients and co-infected patients in comparison to malaria monoinfected patients. This 
decrease in the number of leukocytes is similar to previous research findings that showed mean values of leucocytes less than 5000 cells $/ \mathrm{mm}^{3}$ in both dengue fever and dengue hemorrhagic fever patients [35, 36]. In addition to leucocytes, the platelet count was markedly low in co-infected patients compared to both groups of mono-infected patients. Although the difference is not significant for dengue monoinfected patients. Our results are consistent with the studies in Sri Lanka and Vietnam $[36,37]$ wherein it was shown a synergistic pathogenic mechanism exists. The synergistic pathogenism is attributable to capillary fragility and coagulation disorders in DENV infection. All of these increase the risk of bleeding. Bleeding is rarely reported in malaria infection, although platelet depletion is often observed [38, 39]. Conversely, bleeding is the most feared complication of dengue fever, where in addition to platelet depletion, virus-induced endothelial and liver injury concur to the risk of coagulopathy [40-42]. Anticoagulant heparin, mast cell-specific proteases, cytokines (TNF) and other vasoactive factors products released during primary DENV infection [43] provoke DENV-induced mast cell degranulation. The products released can act on the vascular endothelium and influence the coagulation cascade [44].

Our study has a few limitations. It was not possible to include PCR in this study to confirm dengue infection. In addition, the current study was restricted to out patient only and conducted in single healthcare settings. If the patients who got treated at the hospital level were also included, that could have caused some changes in the results. In fact, the patients included in the study were mainly patients who had come by themselves to the health center and therefore theoretically less symptomatic.

On the other hand, this study had also some strength. This was one of few prospective studies addressing malaria and dengue co-infection and evaluation of hematological parameters in comparison of both single infections in sub Saharan Africa.

\section{Conclusion}

Malaria and dengue are really public health concerns in Burkina Faso. These diseases present the overlapping symptoms; it is important to detect the pathogen presence for best treatment. We showed that co-infection dengue-malaria occurred in $7.01 \%$ of out patient in a peripheral health center of Ouagadougou in Burkina Faso, suggesting that this may not be a rare phenomenon in tropical endemic areas. Dengue and malaria co-infection requires special attention because delayed diagnosis and inappropriate treatment may result in fatal complications. In our study it was not possible to include PCR test for dengue diagnosis confirmation but we recommend this molecular diagnosis test in future study to detect viral
RNA in order to confirm diagnosis and also provide serotype information.

\section{Acknowledgments}

Authors are grateful to Hôpital Paul VI de Ouagadougou for the working facilities and technical assistance. We are also thankful to Laboratoire de Biochimie et d'Immunologie Appliquées of the University Joseph ki-Zerbo, Ouagadougou (Burkina Faso) for the working facilities and assistance in the redaction of this article. Thank to M. Zoubga Adama for Statistical analysis.

\section{Author Contributions}

Study concept and design; HYE and IPD. Sample collection and processing; SK and GMRS. Statistical analysis and interpretation of data; HYE, FT, IPD. Drafting of the manuscript; HYE, FT and IPD. Critical revision of the manuscript for important intellectual content; YT, LS, JS, SG. Study supervision HYE and SK.

\section{Competing Interests}

The authors declare no competing interests.

\section{REFERENCES}

[1] WHO, "World malaria report 2019”, WHO 2019, https://www.who.int/malaria/publications/world-malaria-re port-2019/, (accessed May 13, 2021).

[2] Direction Générale des Etudes et des Statistiques Sectorielles (DGESS). “Annuaire Statistique 2018”. Ministère de la Santé Burkina Faso, 2019, http://cns.bf/IMG/pdf/annuaire_ms_2018.pdf, （accessed May 13, 2021).

[3] Tarnagda Z., Cissé A., Bicaba B. W., Diagbouga S., Sagna T., Ilboudo A. K., Tialla D., Lingani M., Sondo K. A., Yougbaré I., Yaméogo I., Sow H. E., Sakandé J., Sangaré L., Greco R., Muscatello D. J., “Dengue Fever in Burkina Faso, 2016”, Emerging Infectious Diseases, vol. 24, pp. 170-172, 2018. DOI: 10.3201/eid2401.170973

[4] WHO, "World malaria report 2016”, WHO 2016. https://www.who.int/malaria/publications/world-malaria-re port-2016/report/en/, (accessed May 13, 2021).

[5] Ouattara A. K., Nadembega C., Diarra B., Zohoncon T., Yonli A., Obiri-Yeboah D., Belemgnegre M., Ouedraogo P., Pietra V., Simporé J., "Serological diagnosis in suspected dengue cases at Saint Camille Hospital of Ouagadougou: High prevalence of infection among young adults aged 15 to 30 years”, International Journal of Recent Advances in Multidisciplinary Research, vol. 04, 2017.https://www.ijra 
mr.com/issue/serological-diagnosis-suspected-dengue-case s-saint-camille-hospital-ouagadougou-high

[6] Brady O. J., Gething P. W., Bhatt S., Messina J. P., Brownstein J. S., Hoen A. G., Moyes C. L., Farlow A. W., Scott T. W., Hay S. I., "Refining the Global Spatial Limits of Dengue Virus Transmission by Evidence-Based Consensus”, PLoS Neglected Tropical Diseases, vol. 6, p. e1760, 2012. DOI: 10.1371/journal.pntd.0001760

[7] WHO, "World malaria report 2014”, WHO 2014, https://www.who.int/malaria/publications/world_malaria_r eport_2014/en/, (accessed May 13, 2021).

[8] Amarasinghe A., "Dengue Virus Infection in Africa", Emerging Infectious Diseases, 2011. DOI: 10.3201/eid1708.101515.

[9] Ministère de la santé, Burkina Faso. "Flambée de cas de dengue au Burkina Faso. Rapport de situation N²6 du 26 Octobre 2017”, Ministère de la santé, Burkina Faso, https://www.humanitarianresponse.info/sites/www.humani tarianresponse.info/files/documents/files/sitrep_dengue_nd eg26_2017.pdf

[10] Nebie I., Diarra A., Ouedraogo A., Soulama I., Bougouma E. C., Tiono A. B., Konate A. T., Chilengi R., Theisen M., Dodoo D., Remarque E., Bosomprah S., Milligan P., Sirima S. B., "Humoral Responses to Plasmodium falciparum Blood-Stage Antigens and Association with Incidence of Clinical Malaria in Children Living in an Area of Seasonal Malaria Transmission in Burkina Faso, West Africa”, Infection and Immunity, vol. 76, pp. 759-766, 2008. DOI: 10.1128/IAI.01147-07.

[11] Lim J. K., Seydou Y., Carabali M., Barro A., Dahourou D. L., Lee K. S., Nikiema T., Namkung S., Lee J.-S., Shin M. Y., Bonnet E., Kagone T., Kaba L., Edwards T., Some P.-A., Yang J. S., Alexander N., Yoon I.-K., Ridde V., "Clinical and epidemiologic characteristics associated with dengue during and outside the 2016 outbreak identified in health facilitybased surveillance in Ouagadougou, Burkina Faso”, PLOS Neglected Tropical Diseases, vol. 13, 2019. DOI: 10.1371/journal.pntd.0007882

[12] Wang S. M., Sekaran S. D., "Early diagnosis of Dengue infection using a commercial Dengue Duo rapid test kit for the detection of NS1, IGM, and IGG", The American journal of tropical medicine and hygiene, vol. 83, no. 3, pp. 690-695, 2010. DOI: 10.4269/ajtmh.2010.10-0117.

[13] Kima D., Hien Y. E., Nikièma M., Sanou F., Zoungrana C., Kafando E., Traoré Y., "The main BCR ABL mRNA transcript types and hematological features of newly diagnosed chronic myeloid leukemia in Burkina Faso”, World Cancer Research Journal, vol. 7, 2020. DOI: 10.32113/wcrj_20207_1613

[14] Singh B., "Dengue outbreak in 2006: Failure of public health system?”, Indian Journal of Community Medicine, vol. 32, pp. 99-100, 2007. DOI: 10.4103/0970-0218.35643

[15] Lim J. K., Seydou Y., Carabali M., Barro A., Dahourou D. L., Lee K. S., Nikiema T., Namkung S., Lee J.-S., Shin M. Y., Bonnet E., Kagone T., Kaba L., Edwards T., Some P.-A., Yang J. S., Alexander N., Yoon I.-K., Ridde V., "Clinical and epidemiologic characteristics associated with dengue during and outside the 2016 outbreak identified in health facility based surveillance in Ouagadougou, Burkina Faso”, PLOS Neglected Tropical Diseases, vol. 13, 2019.
[16] Portugal S., Obeng-Adjei N., Moir S., Crompton P. D. Pierce S. K., "Atypical memory B cells in human chronic infectious diseases: An interim report”, Cellular Immunology, vol. 321, pp. 18-25, 2017. DOI: 10.1016/j.cellimm.2017.07.003

[17] Aponte J. J., Menendez C., Schellenberg D., Kahigwa E., Mshinda H., Vountasou P., Tanner M., Alonso P. L., “Age Interactions in the Development of Naturally Acquired Immunity to Plasmodium falciparum and Its Clinical Presentation”, PLoS medicine, vol. 4, p. e242, 2007. DOI: 10.1371/journal.pmed.0040242

[18] yg-Cornejo V., Ioannidis L. J., Ly A., Chiu C. Y., Tellier J., Hill D. L., Preston S. P., Pellegrini M., Yu D., Nutt S. L., Kallies A., Hansen D. S., "Severe Malaria Infections Impair Germinal Center Responses by Inhibiting $\mathrm{T}$ Follicular Helper Cell Differentiation”, Cell reports, vol. 14, pp. 68-81, 2016. DOI: 10.1016/j.celrep.2015.12.006

[19] Diallo A., Sié A., Sirima S., Sylla K., Ndiaye M., Bountogo M., Ouedraogo E., Tine R., Ndiaye A., Coulibaly B., Ouedraogo A., Faye B., Ba E. H., Compaore G., Tiono A., Sokhna C., Yé M., Diarra A., Bahmanyar E. R., De Boer M., Pirçon J.-Y., Usuf E. A., "An epidemiological study to assess Plasmodium falciparum parasite prevalence and malaria control measures in Burkina Faso and Senegal”, Malaria journal, vol. 16, no. 1, 2017. DOI: 10.1186/s12936-017-1715-1

[20] Owusu-Agyei S., Asante K. P., Adjuik M., Adjei G., Awini E., Adams M., Newton S., Dosoo D., Dery D., Agyeman-Budu A., Gyapong J., Greenwood B., Chandramohan D., "Epidemiology of malaria in the forest-savanna transitional zone of Ghana”, Malaria journal, vol. 8, no. 1, 2009. DOI: 10.1186/1475-2875-8-220

[21] Konaté A. T., Yaro J. B., Ouédraogo A. Z., Diarra A., Gansané A., Soulama I., Kangoyé D. T., Kaboré Y., Ouédraogo E., Ouédraogo A., Tiono A. B., Ouédraogo I. N., Chandramohan D., Cousens S., Milligan P. J., Sirima S. B., Greenwood B., Diallo D. A., "Intermittent Preventive Treatment of Malaria Provides Substantial Protection against Malaria in Children Already Protected by an Insecticide-Treated Bednet in Burkina Faso: A Randomised, Double-Blind, Placebo-Controlled Trial”, PLoS medicine, vol. 8, p. e1000408, 2011. DOI: 10.1371/journal.pmed.100 0408

[22] Lima J. R. C., Rouquayrol M. Z., Callado M. R. M., Guedes M. I. F., Pessoa C., "Interpretation of the presence of IgM and IgG antibodies in a rapid test for dengue: analysis of dengue antibody prevalence in Fortaleza City in the 20th year of the epidemic”, Revista da Sociedade Brasileira de Medicina Tropical, vol. 45, pp. 163-167, 2012. DOI: https://doi.org/10.1590/S0037-86822012000200005

[23] Ridde V., Carabali M., Ly A., Druetz T., Kouanda S., Bonnet E., Haddad S., "The Need for More Research and Public Health Interventions on Dengue Fever in Burkina Faso”, PLOS Neglected Tropical Diseases, vol. 8, 2014. DOI: 10.1371/journal.pntd.0002859

[24] Ridde V., Agier I., Bonnet E., Carabali M., Dabiré K. R., Fournet F., Ly A., Meda I. B., Parra B., "Presence of three dengue serotypes in Ouagadougou (Burkina Faso): research and public health implications", Infectious Diseases of Poverty, vol. 5, 2016. DOI: 10.1186/s40249-016-0120-2 
[25] Garg A., Rao J. G., Upadhyay G. C., Sakhuja S., "Prevalence of dengue among clinically suspected febrile episodes at a teaching hospital in North India”, Journal of Infectious Diseases and Immunity, vol. 3, pp. 85-89, 2011. Available online at http://www.academicjournals.org/JIDI. ISSN 2141-2375 @2011 Academic Journals

[26] Gupta E., Dar L., Kapoor G., Broor S., "The changing epidemiology of dengue in Delhi, India”, Virology Journal, vol. 3, 2016. DOI: 10.1186/1743-422X-3-92

[27] Kumar A., Rao C., Pandit V., Shetty S., Bammigatti C., Samarasinghe C., "Clinical manifestations and trend of dengue cases admitted in a tertiary care hospital, Udupi district, Karnataka”, Indian Journal of Community Medicine, vol. 35, no. 3, pp. 386-390, 2010. DOI: $10.4103 / 0970-0218.69253$

[28] Patankar M., Patel B., Gandhi V., Shah P., Vegad M., "Seroprevalence of Dengue in Gujarat, Western India: A study at a tertiary care hospital”, International Journal of Medical Science and Public Health, vol. 3, no. 1, pp. 16-18, 2014. DOI: 10.5455/ijmsph.2013.140920131

[29] Deparis X., Maréchal V., Matheus S. X., "Mécanismes physiopathologiques de la dengue: revue critique des hypotheses”, Médecine Tropicale, vol. 69, pp. 351-357, 2009,

https://www.semanticscholar.org/paper/Mécanismes-physi opathologiques-de-la-dengue-\%3A-revue-Deparis-Maréch al/812dee6ea95feb16ee4ad5385dc4e1590d7fbf44

[30] Mamoudou S., Boushab B. M., "Formes hémorragiques de Dengue observées dans le service des maladies infectieuses du CHU Yalgado Ouédraogo, Burkina Faso”, Pan African Medical Journal, vol. 23, 2016. DOI: 10.11604/pamj.2016. 23.168.9234

[31] Magalhães B. M. L., Siqueira A. M., Alexandre M. A. A., Souza M. S., Gimaque J. B., Bastos M. S., Figueiredo R. M. P., Melo G. C., Lacerda M. V. G., Mourão M. P. G., "P. vivax Malaria and Dengue Fever Co-infection: A Cross-Sectional Study in the Brazilian Amazon”, PLoS Neglected Tropical Diseases, vol. 8, p. e3239, 2014. DOI: 10.1371/journal.pntd.0003239

[32] Mohapatra M. K., Patra P., Agrawala R., "Manifestation and outcome of concurrent malaria and dengue infection”, J Vector Borne Dis, vol. 49, pp. 262-265, 2012, https://www.jvbd.org/temp/JVectorBorneDis494262-7697 746_212257.pdf

[33] Epelboin L., Hanf M., Dussart P., Ouar-Epelboin S., Djossou F., Nacher M., Carme B., "Is dengue and malaria co-infection more severe than single infections? A retrospective matched-pair study in French Guiana", Malaria journal, vol. 11, 2012. DOI: 10.1186/1475-2875-1 $1-142$

[34] Assir M. Z. K., Masood M. A., Ahmad H. I., "Concurrent dengue and malaria infection in Lahore, Pakistan during the 2012 dengue outbreak”, International Journal of Infectious Diseases vol. 18, pp. 41-46, 2014. DOI: 10.1016/j.ijid.2013.09.007

[35] Ralapanawa U., Alawattegama A. T. M., Gunrathne M.,
Tennakoon S., Kularatne S. A. M., Jayalath T., "Value of peripheral blood count for dengue severity prediction", BMC Research Notes, vol. 11, no. 1, 2018. DOI: 10.1186/s13104-018-3505-4

[36] Jayadas T. T. P., Kumanan T., Arasaratnam V., Gajapathy K., Surendran S. N., "The clinical profile, hematological parameters and liver transaminases of dengue NS1 Ag positive patients admitted to Jaffna Teaching Hospital, Sri Lanka”, BMC Research Notes, vol. 12, no. 1, 2019. DOI: 10.1186/s13104-019-4655-8

[37] Lam P. K., Ngoc T. V., Thu Thuy T. T., Hong Van N. T., Nhu Thuy T. T., Hoai Tam D. T., Dung N. M., Hanh Tien N. T., Thanh Kieu N. T., Simmons C., Wills B., Wolbers M., "The value of daily platelet counts for predicting dengue shock syndrome: Results from a prospective observational study of 2301 Vietnamese children with dengue”, PLOS Neglected Tropical Diseases, vol. 11, p. e0005498, 2017. DOI: 10.1371/journal.pntd.0005498

[38] Kochar D. K., Das A., Kochar A., Middha S., Acharya J., Tanwar G. S., Gupta A., Pakalapati D., Garg S., Saxena V., Subudhi A. K., Boopathi P. A., Sirohi P., Kochar S. K., "Thrombocytopenia in Plasmodium falciparum, Plasmodium vivax and mixed infection malaria: A study from Bikaner (Northwestern India)”, Platelets, vol. 21, pp. 623-627, 2010. DOI: 10.3109/09537104.2010.505308

[39] Lacerda M. V. G., Mourão M. P. G., Coelho H. C. C., Santos J. B., “Thrombocytopenia in malaria: who cares?”, Mem Inst Oswaldo Cruz, Rio de Janeiro, vol. 106, pp. 52-63, 2011. DOI: 10.1590/S0074-02762011000900007

[40] Mourão M. P. G., Lacerda M. V. G., Macedo V. O., Santos J. B., "Thrombocytopenia in patients with dengue virus infection in the Brazilian Amazon”, Platelets, vol. 18, pp. 605-612, 2007. DOI: 10.1080/09537100701426604

[41] Alonzo M. T. G., Lacuesta T. L. V., Dimaano E. M., Kurosu T., Suarez L. C., Mapua C. A., Akeda Y., Matias R. R., Kuter D. J., Nagata S., Natividad F. F., Oishi K., "Platelet Apoptosis and Apoptotic Platelet Clearance by Macrophages in Secondary Dengue Virus Infections”, The Journal of infectious diseases, vol. 205, pp. 1321-1329, 2012. DOI: 10.1093/infdis/jis180

[42] Costa V. V., Fagundes C. T., Souza D. G., Teixeira M. M., "Inflammatory and Innate Immune Responses in Dengue Infection Protection versus Disease Induction", The American Journal of Pathology, vol. 182, pp. 1950-1961, 2013. 10.1016/j.ajpath.2013.02.027

[43] Syenina A., Jagaraj C. J., Aman S. A., Sridharan A., John A. L. S., "Dengue vascular leakage is augmented by mast cell degranulation mediated by immunoglobulin Fc $\gamma$ receptors", eLife Immunology Microbiology and infectious disease, vol. 4, 2015. DOI: 10.7554/eLife.05291

[44] John A. L. S., Rathore A. P., Raghavan B., Ng M.-L., Abraham S. N., "Contributions of mast cells and vasoactive products, leukotrienes and chymase, to dengue virus-induced vascular leakage”, eLife Immunology Microbiology and infectious disease, vol. 2, 2013. 10.7554/eLife.00481 